\title{
MULHERES, MÃES E PALAVRAS: DUAS LEOAS RUGEM E IMPRIMEM SUAS LETRAS EMPODERADAS NA ESCRITA LITERÁRIA
}

\author{
FERNANDA FOCHI NOGUEIRA INSFRAN (UFF) ${ }^{1}$ \\ ANA GUIMARÃES CORREAA RAMOS MUNIZ (UFF/INFES) $)^{2}$
}

\begin{abstract}
RESUMO: Este artigo pretende apresentar as problematizações oriundas das obras de Carolina Maria de Jesus (Quarto de Despejo: Diário de uma Favelada) e Manuela D’Ávila (Revolução Laura), a fim de que se promova uma reflexão acerca do lugar da mulher, e principalmente da mulher-mãe, na(s) sociedade(s). Nosso existir resistindo é amplificado por mãos feministas que, assim como Carolina e Manuela, permanecem ecoando gritos de liberdade. A leitura de tais mulheres nos faz convites à reflexão. Encontramos Arruzza, Bhattacharya e Fraser (2019) falando sobre o feminismo que, de fato, precisamos e queremos. Aprendemos com Creenshaw (2002), que cunha a interseccionalidade e traz luz às discriminações sofridas por mulheres de diferentes classes, raças/etnias e culturas, apenas para citar algumas dentre tantas. Djamila Alves Ribeiro (2018) e bell hooks (2013) nos conduzem à realidade triste de ainda coexistirmos com aqueles marcados por falta de empatia e sororidade. Todas essas mãos guiaram as nossas na costura das palavras que, com a tinta da literatura, aqui se imprimem. As palavras das autoras das obras referenciadas ecoam revelando discriminações, ressoam denunciando o discurso de ódio e reverberam anunciando a força potente da mulher que não se cala.
\end{abstract}

PALAVRAS-CHAVE: Mulher-mãe. Empoderamento. Leitura empática.

ABSTRACT: This article intends to present the problematizations that arose from the works of Carolina Maria de Jesus (Child of the Dark: The Diary of Carolina Maria de Jesus) and Manuela D'Avila (Revolução Laura, title in English not available), in order to promote a reflection on the place of women, and especially of women who are mothers, in the society (societies). Our resisting existence is amplified by feminist hands that, like Carolina and Manuela, continue to echo cries of freedom. The reading of such women invites us to a deep reflection. We find Arruzza, Bhattacharya, and Fraser (2019) talking about the feminism that we really need and want. We learn from Creenshaw (2002), who wedge intersectionality and brings light to the discrimination suffered by women of different classes, races / ethnicities and cultures, just to name a few among many. Djamila Alves Ribeiro (2018) and bell hooks (2013) lead us to the sad reality of still coexisting with those marked by lack of empathy and sorority. All these hands guided ours in the sewing of the words which, with the ink of literature, are printed here. The words from the authors of the referenced works echo revealing discrimination, resound denouncing the discourse of hatred and reverberate by announcing the powerful force of the woman who does not remain silent.

KEYWORDS: Woman-mother. Empowerment. Empathic reading.

\section{INTRODUÇÃO}

Mulher, negra, migrante, favelada, catadora de papel, mãe. Carolina Maria de Jesus poderia ser reconhecida através de tais ou demais nomes. Um título, porém, seria impensado caso Carolina cedesse ao contexto hostil que a cercava: escritora. Seu muito amor pelas palavras não permitiu que a hostilidade a parasse, na verdade. Ela não apenas aprendera a ler e escrever, mas também a libertar-se através das letras. Moradora da favela do Canindé, na

\footnotetext{
1 Professora Adjunta na Universidade Federal Fluminense (campus Santo Antônio de Pádua), e-mail: nandainsfran79@gmail.com

2 Mestranda em Ensino pela Universidade Federal Fluminense (UFF/INFES); professora EBTT no Instituto Federal Fluminense (IFF), e-mail: ana.ramos@iff.edu.br
} 


\section{$=$ TRAMA $=$}

capital paulista, Carolina catava papéis e registrava a rotina da favela em cadernos que encontrava em meio ao material que recolhia.

Carolina escrevia o que sentia e via. Ameaçava denunciar infratores ao torná-los personagens em suas escritas e, assim, acabou sendo descoberta por um jornalista, Audálio Dantas. Seus diários foram transformados em livro. Quarto de Despejo: Diário de uma Favelada, publicado em 1960, tornou-se um best-seller, vendido em inúmeros países e traduzido para vários idiomas.

Suas escritas são, hoje, objeto de muitas outras escritas. Carolina escreveu "em Carolina", não se atendo a um rigor normativo, mas respeitando seu atravessamento, manifesto através de suas palavras. A autora lutava por sua sobrevivência, assim como a dos filhos, e sua batalha era travada contra a escravatura da fome, bem como as várias interdições que sua condição feminina Ihe impunha.

A vida de Manuela D’Ávila difere, inicialmente, à de Carolina. Reconhecida internacionalmente, ganhadora de prêmios, autora de leis e política hábil, vereadora mais jovem da história de Porto Alegre e deputada mais votada do Rio Grande do Sul, a filha de uma juíza e de um professor universitário não é uma favelada. Contudo, todos esses privilégios não a pouparam de violências, assim como as que Carolina Maria de Jesus sofreu.

Revolução Laura, livro publicado em 2019, é puro afeto. Manuela inunda as páginas de sua obra, por nós tida como reunião de pensamentos e paixões verbalizadas, com sentimentos que marcaram e marcam sua história como "MMMM" (D’ÁVILA, 2019, p. 95): Manuela, mãe, mulher e militante.

Embora consciente de todos os privilégios que possui, Manuela é mais consciente ainda dos privilégios que outras mulheres (ainda) não possuem. Uma escrita sem firulas mostra os registros de uma mulher que percorreu dezenove estados brasileiros, acompanhada por Laura, sua filha de dois anos, ao tornar-se candidata à Presidência da República em novembro de 2017 e à Vice-Presidência em agosto de 2018.

O livro de Manuela D’Ávila é feito de relatos. Relatos de violência física, verbal, moral e política de gênero. Violência contra uma menina de dois anos. Violência contra a própria família. Relatos de tratamentos desiguais num ambiente de política masculina e machista. O feminismo vivido como "contrário de solidão" (Ibid., p.121). A maternidade como escolha, nada romantizada.

Uma leitura descuidada de Quarto de Despejo: Diário de uma Favelada e Revolução Laura não levaria em consideração as muitas afinidades existentes entre Carolina e Manuela. Os cinquenta e nove anos que distanciam as duas obras não foram capazes de desorientar a força das vozes das autoras. A grande verdade é que muito embora desejássemos já existir uma revolução no olhar sobre a figura da mulher, que é mãe e militante, há ainda hoje aquelas que se encontram em situação de despejo.

Refletir sobre a condição/posição-sujeito da mulher e da mulher-mãe apresentada nas duas obras nos convoca à leitura de escritoras feministas de diferentes áreas, como psicologia, antropologia e filosofia. As potentes narrativas de Carolina e Manuela nos aproximam das discussões sobre as desiguais ocupações dos espaços público e privado por homens e mulheres (BIROLI, 2014), forjada na cultura machista e patriarcal para manter mulheres distantes das decisões políticas e, finalmente, a importância de projetarmos uma luta feminista que considere os atravessamentos/recortes de classe, raça, geração, orientação sexual, a fim de que seja possível legitimar o lugar de fala tanto das mulheres brancas, escolarizadas e privilegiadas socialmente, como das pretas pobres e faveladas (HOOKS, 2013; ARRUZZA, BHATTACHARYA, FRASER, 2019; RIBEIRO, 2017). 


\title{
$=$ TRAMA $=$
}

Diante do que foi brevemente dito, este artigo objetiva aliviar os pensamentos que, naturalmente, afloram naquele que lê Carolina Maria de Jesus e Manuela D’Ávila de maneira empática, bem como irrompem do contato com as demais leituras que cerziram nossa colcha de palavras. Os rugidos oriundos dessas leoas ecoam e produzem sensações que aqui são transformadas em letras, decididamente mantidas como nos foram apresentadas, ainda que contrariem normas gramaticais ou incomodem gramatiqueiros e ortografistas. E mais: além de sensações, tais mulheres e escritoras provocam o desejo por movimento. A começar desta escrita.

\section{UMA LEITURA EMPÁTICA DE CAROLINA MARIA DE JESUS}

Carolina Maria de Jesus, através de sua escrita, existe. Infelizmente, ainda é possível encontrar pessoas que essa grande mulher ainda não conhecem. Poderíamos levantar os muitos motivos que explicariam tal desconhecimento, dentre eles o fato de sua escrita não ser fiel à polidez acadêmica ou até mesmo o desdém por Carolina se tratar de uma mulher preta, assim como ela mesma se intitulava, pobre e desprestigiada. Para nós, contudo, Carolina e suas palavras são pura denúncia, coragem e empoderamento.

A autora escrevia na intenção de viver e sobreviver ao caos que the cercava, além de desabafar através das palavras que viraram cicatrizes em páginas de seu diário. Em dezesseis de julho de 1955, ela diz:

\begin{abstract}
Cheguei em casa, aliás no meu barracão, nervosa e exausta. Pensei na vida atribulada que eu levo. Cato papel, lavo roupa para dois jovens, permaneço na rua o dia todo. E estou sempre em falta. [...] Saí indisposta, com vontade de deitar. Mas, o pobre não repousa. Não tem o previlegio de gosar descanço (JESUS, 2014 [1960], p. 12).
\end{abstract}

A força do relato de Carolina chega a perturbar. Anos decorreram após tal fala e ainda encontramos pessoas que vivem a realidade descrita pela autora. Suas palavras correram e correm o mundo, ecoando a real impossibilidade de repouso do pobre, bem como seu desmoralizado direito ao simples descanso.

Direito. Essa palavra, infelizmente carregada de controvérsias, assemelha-se à água na peneira, em "O menino que carregava água na peneira", de Manoel de Barros. Quanto mais lutava por seus direitos, mais Carolina parecia vê-los escorrendo por seus dias peneirados e escassos de muitas coisas, inclusive de sororidade. Os relatos do dia dezoito de julho de 1955 viriam a denunciar tal ausência:

Cheguei no inferno. Abri a porta e pus os meninos para fora. A D. Rosa, assim que viu o meu filho José Carlos começou a impricar com ele. Não queria que o menino passasse perto do barracão dela. Saiu com um pau para espancá-lo (...). Às vezes eu saio, ela vem até minha janela e joga o vaso de fezes nas crianças. Quando eu retorno, encontro os travesseiros e as crianças fétidas. Ela odeia-me. Diz que sou preferida pelos homens bonitos e distintos. E ganho mais dinheiro do que ela (JESUS, 2014 [1960], p. 15; 16).

A propagação do discurso de ódio, a retaliação, bem como a competição entre mulheres, motivados por uma sociedade machista e patriarcal não são, definitivamente, uma infelicidade da contemporaneidade. A grande questão é que tais comportamentos compõem não apenas um imaginário social, mas também nossa realidade, e não dependem da presença de um homem para serem disseminados. A violência é reproduzida, em muitos momentos, por nós, mulheres. 


\section{$=$ TRAMA $=$}

É importante ressaltar, contudo, que não nos cabe culpabilizar e violentar, pela enésima vez, a figura da mulher, da mulher-mãe. A leitura de Carolina e de nossa realidade promovem a seguinte reflexão: é exatamente neste nosso território, repleto de rudeza, machismo, avesso à diferença e carente de empatia, que questionamentos e enfrentamentos precisam e merecem ganhar espaço. Seguindo as palavras de Paulo Freire (2000), seriam a possibilidade de a consciência do mundo e a consciência de si ocuparem os seus devidos lugares.

A consciência do mundo e a consciência de mim me fazem um ser não apenas no mundo, mas com o mundo e com os outros. Um ser capaz de intervir no mundo e não só de a ele me adaptar. É neste sentido que mulheres e homens interferem no mundo enquanto os outros animais apenas mexem nele. É por isso que não apenas temos história, mas fazemos a história que igualmente nos faz e que nos torna, portanto, históricos (FREIRE, 2000, p. 6).

Consciência não faltava à Carolina. Ela sabia que a escrita era a força libertadora que possuía. Ao escrever e arquivar tanto papéis quanto memórias, Carolina empoderava-se. Ao guardar seus diários, a autora não se propunha ao acúmulo e ocupação de espaço em seu barracão, mas a definir-se como mulher-mãe-escritora-ativa. E Carolina suportava o peso de ser uma mulher e mãe sozinha, através do auxílio de seus manifestos em formato de diário.

Que suplicio catar papel atualmente! Tenho que levar a minha filha Vera Eunice. Ela está com dois anos, e não gosta de ficar em casa. Eu ponho o saco na cabeça e levo-a nos braços. Suporto o peso do saco na cabeça e suporto o peso da Vera Eunice nos braços. Tem hora que revolto-me. Depois domino-me. Ela não tem culpa de estar no mundo. Refleti: preciso ser mais tolerante com os meus filhos. Eles não tem ninguem no mundo a não ser eu. Como é pungente a condição de mulher sozinha sem um homem no lar. Aqui, todas impricam comigo. Dizem que falo muito bem. Que sei atrair os homens. (...) Quando fico nervosa não gosto de discutir. Prefiro escrever. Todos os dias eu escrevo. Sento no quintal e escrevo (JESUS, 2014 [1960], p. 22).

As garras dessa leoa arranham. A obra de Carolina é selvagem e foge à escrita domesticada à qual somos comumente apresentadas. Os desdobramentos que a autora propõe são amplamente expostos em sua escrita crítica. Críticas, por sinal, são marcas registradas em seu diário.

Carolina critica o tratamento que pobres e favelados recebiam (e ainda recebem), bem como a forma como as mulheres tratavam mulheres na favela (mal que ainda se alastra e arrasta por vários outros lugares). Carolina critica os próprios políticos e governantes, com direito a avisos: "O que eu aviso aos pretendentes a politica, é que o povo não tolera a fome. É preciso conhecer a fome para saber descrevê-la" (JESUS, 2014 [1960], p. 29). Segundo a autora, a fome era da cor amarela e o Brasil precisava ser dirigido por alguém que tivesse aprendido com aquela verdade, alguém que protegesse os favelados e não apenas seus próprios interesses.

Quem nos protege é o povo e os Vicentinos. Os políticos só aparecem aqui nas epocas eleitoraes. O senhor Cantidio Sampaio quando era vereador em 1953 passava os domingos aqui na favela. Ele era tão agradavel. Tomava nosso café, bebia nas nossas xicaras. Ele nos dirigia as suas frases de viludo. Brincava com nossas crianças. Deixou boas impressões por aqui e quando candidatou-se a deputado venceu. Mas na Camara dos Deputados não criou um projeto para beneficiar o favelado. Não nos visitou mais (JESUS, 2014, p. 32).

Qual seria, então, o motivo do apagamento e esquecimento, durante um bom tempo, de uma autora tão relevante como Carolina Maria de Jesus? Segundo Meihy (1998, p. 89), "o 


\section{$=$ TRAMA $=$}

livro de Carolina foi evitado pelos editores que o viam como perigoso e passível de uma censura". A obra era, na verdade, uma denúncia em um momento conturbado da história nacional, além de também se deslocar de toda uma produção intelectual no Brasil produzida. Ademais, é no mínimo estranho Carolina não ter feito parte de um grupo que, segundo Lajolo (1995, p. 10), era composto por "mulheres com ideias na cabeça e pena na mão". Podendo ter sido uma raiz literária feminista, a autora foi vítima da impiedade da elite nacional.

Ainda que tenha se tornado conhecida rapidamente após a publicação de seu livro, nem a própria Carolina teve noção do que acontecia. Meihy (1998, p. 88) aponta para o fato de a autora, "no dia do lançamento do livro, ter saído para catar papel, pois não tinha dinheiro para a alimentação dos filhos". Apesar de ter tido a vida encenada em teatro, na televisão e também ter gravado discos, a história desta mulher parece ter interessado àquela sociedade apenas como drama. Apenas.

A história de Carolina a nós interessa. Muito. Sua escrita era e é um manifesto. Erros gramaticais não são erros, mas expressão da sua sensibilidade transgressora e incalável. A literatura tem esse poder e Carolina foi poderosa. A mulher, mãe, preta, favelada e escritora brada. Sempre. Retumbantes, sim, são as palavras de Carolina Maria de Jesus.

\section{UMA LEITURA EMPÁTICA DE MANUELA D'ÁVILA}

O livro de Manuela D'Ávila é, literalmente, o trabalho de uma compositora. Sem pedir licença poética (como se isso necessário fosse), Revolução Laura surge de uma união de pensamentos, angústias, reflexões, honestidade, militância e maternagem. As palavras espontâneas e carregadas de pessoalidade formam um conjunto de ensaios amorosos dispostos em quase duzentas páginas. Ensaios dialógicos, com tons de diários sem a preocupação de datas. Ensaios que "encarnam as palavras". ${ }^{3}$

Em dezoito anos de vida pública, Manuela sofreu (e sofre) violências. Pelos mesmos anos, a mulher-política não pôde unicamente lutar pelos ideais que defendia, mas precisou mostrar que questões estéticas a ela atribuídas não deveriam ser mais noticiadas do que suas conquistas.

Lembro como se fosse hoje do dia em que ouvi: "Meio antipático você dizer que não quer ser chamada de bonita. Quem não quer?". Eu! Eu não queria, não sabia ser. Então, internamente me fechei. Externamente aceitei todas as entrevistas para as quais fui chamada. Parece contraditório. Não é. Me chamavam pra falar sobre "ser bonita". Eu falava sobre ser de luta (D’ÁVILA, 2019, p. 25 e 26).

Ser-em-luta retrata Manuela D’Ávila. A autora relata algumas lutas que precisou enfrentar e ser mulher foi uma delas. A consciência de seus privilégios, assim como sua convicção de a desigualdade socioeconômica afetar mulheres de forma muito mais impiedosa, fizeram com que Manuela lutasse, desde os dezessete anos, por justiça social.

\footnotetext{
Uma de nós ser assediada a cada dois segundos, tem nome. Sermos responsabilizadas pela violência que sofremos, tem nome. Receber menos salário pelo mesmo trabalho, tem nome. Estabelecerem padrões físicos doloridos e inalcançáveis para nós, tem nome. Sofrer violência física, ser assassinada e ouvir que o amor pode matar, tem nome. Parir e ficar desempregada tem nome. Ser invisível na política, tem nome. A ideia de que somos inferiores, menos livres, menos donas de nossos corpos e mentes, menos merecedoras de direitos, tem nome. O nome disso é machismo (D’ÁVILA, 2019, p.154).
}

\footnotetext{
${ }^{3}$ O termo em destaque foi utilizado por Eliane Brum, em sua coluna no El Pais, na publicação do dia 12/04/2019, disponível em https://brasil.elpais.com/brasil/2019/04/10/opinion/1554907780_837463.html.

Eliane Brum, a propósito, é outra autora cuja escrita é penetrante.
} 


\title{
$=$ TRAMA $=$
}

E "ser feminista" não é o contrário de "ser machista". Segundo a autora, "feminismo é equidade, direitos iguais, direito à vida sem violência, direito a sermos donas dos nossos corpos e mentes" (D'ÁVILA, 2019, p. 155). Denominar-se feminista fez e faz com que Manuela D’Ávila seja incompreendida e violentada por muitos, sobretudo por aqueles (e infelizmente aquelas) que ignoram o real sentido de se "lutar como uma garota".

\begin{abstract}
Há exatos vinte anos, eu fiz uma opção, como uma garota, de lutar por coisas que são as mais importantes. Nós lutamos como garotas quando nós não nos conformamos com a ideia de que existe um homem ou uma mulher melhor que outro homem e que outra mulher, ou que existe um jovem que pode viver e um outro que é fuzilado. Nós lutamos como garotas e como garotos quando não nos conformamos com a ideia de que existem crianças que são como a minha filha e outras crianças que não têm acesso a absolutamente nada. (...) mais do que lutar com uma mulher ou lutar desde o lugar de fala de uma mulher, estou trazendo o que muitas vezes é visto como defeito da juventude, mas que outras tantas vezes é a maior qualidade, que é a rebeldia, que é a inconformidade (...). Isso é lutar como uma garota! (D’ÁVILA, 2019, p. 20)
\end{abstract}

E essa garota-mulher-política é garota-mulher-política-mãe. Todas essas numa única Manuela, que também luta pelos direitos de Laura, sua filha. Uma linda menina de cachinhos passeia pelas páginas do livro. Seus passos podem não ser com palavras por ela escritas, afinal, Laura ainda não completou três anos. Sua existência, contudo, motiva e desperta a força de cada sentimento por sua mãe relatado.

Fotografias azuladas de mãe e filha/filha e mãe abrilhantam cada folha cortadora de textos. Na verdade, a fotografia é um texto que complementa cada fala empapada de afeto. As experiências vividas da relação entre Manuela e Laura não nos caem como proposta de receita infalível ou invejável a ser seguida. Ao contrário: realidades como amamentação em meio-fio, cocô em entrevista com figura internacional e choros advindos de esgotamentos são alguns dos vários cenários a nós apresentados.

O amor que tem por Laura é sentido por aquele que lê Manuela. Entretanto, seu amor não é limitado à Laura, uma pequena que, segundo a própria mãe, já tem o melhor. A mãe de Laura também escolheu se mobilizar para que outras crianças tenham o melhor. A maternidade despertou ainda mais a vivência empática desta mulher. A maternidade foi uma escolha de Manuela.

Ela sabia que poderia ser feliz não sendo mãe. Sabia-se inteira e realizada antes da chegada de uma filha ou filho. Ainda assim, decidiu engravidar. Sua gravidez não foi fruto de uma relação abusiva ou violenta. Ela tinha um companheiro, alguém com quem dividir responsabilidades. Ela tinha condições financeiras para cuidar de sua criança, afinal, Manuela possuía estabilidade profissional.

Manuela não nega estar num lugar de vantagem em relação a muitas outras mulheres, que ainda entendem a maternidade como compulsória, foram ou são vítimas de relacionamentos arbitrários, têm filhas ou filhos sem registro ou cuidado paterno, ou mesmo aquelas que perdem seus empregos após a licença-maternidade. Embora saiba e cite todos os seus privilégios, Manuela embandeira a máxima do não-umbigocentrismo e reivindica, sim, o lugar de fala e o direito da mulher, seja ela mãe ou não.

Ser alvo de agressões de qualquer tipo provoca feridas. Todavia, a dor revisitada por Manuela pulsa quando Laura, ainda com menos de dois meses, é agredida, com batidas em seu pequeno corpo quando pendurado no sling no colo da mãe, por uma mulher inflamada por uma notícia falsa. A agressão trouxe medo à Manuela. Ainda bem que o medo foi aquele que 


\section{$=$ TRAMA $=$}

não paralisa. Ainda bem que a flor ainda brota no meio do asfalto, assim como Manuela D'Ávila aponta. Ainda bem que o “tamo' juntas!" (D'ÁVILA, 2019, p. 99) é seu e nosso refolgo.

\section{ECOS DAS VOZES FEMININAS}

Leituras empáticas precisam da fruição que escritas também proporcionam. Na realidade, as vozes das autoras nos causaram sentimentos quase tangíveis e que, muitas vezes, são tidos por antagônicos. Amor, ódio, prazer, pavor. A inércia não coaduna com tais sentimentos, muito menos com a resistência. Resistir é existir. E nossa existência é amplificada com a ajuda de algumas autoras feministas que, assim como Carolina e Manuela, lutaram e lutam para fazer ecoar gritos de liberdade, equidade e sororidade.

Ambas as obras nos apresentam histórias de vidas marcadas por violências naturalizadas pelo machismo e pelo patriarcado. Comparar a vivência de duas mulheres-mães de tempos, espaços, raças e classes tão distintas nos traz a exata medida da importância de pensarmos num "feminismo para os 99\%", conforme defendem Arruzza, Bhattacharya e Fraser (2019) no livro-manifesto "O feminismo dos 99\%, um manifesto". Este livro discorre sobre que tipo de feminismo nós precisamos e queremos. Um feminismo que seja antirracista, antiLGBTfóbico, ecossocialista, internacionalista e, sobretudo, anticapitalista. Um feminismo que não cause medo ou repúdio, que seja compreendido pelas mulheres como o caminho para a equidade, liberdade e autonomia indispensáveis às relações saudáveis que almejamos viver. Sobretudo um feminismo interseccional, que possibilite "a garantia de que todas as mulheres sejam beneficiadas pela ampliação da proteção dos direitos humanos baseados no gênero" (CRENSHAW, 2002, p.174). Segundo a mesma autora, é necessário que "se dê atenção às várias formas pelas quais o gênero intersecta-se com uma gama de outras identidades e ao modo pelo qual essas intersecções contribuem para a vulnerabilidade particular de diferentes grupos de mulheres" (CRENSHAW, 2002, p. 174).

Trazer, mesmo que brevemente a discussão sobre interseccionalidade - termo cunhado por Kimberlé Crenshaw (2002), professora da Universidade da Califórnia, durante um encontro de especialistas em aspectos da discriminação racial relativos ao gênero - nos parece muito pertinente para pensarmos na construção de um feminismo para os 99\%. Acreditamos que o feminismo só irá se consolidar como um modus operandi das relações sociais quando a intersecção de discriminações que sofrem mulheres de diferentes classes, raças/ etnias, culturas etc forem contempladas e tiverem lugar na luta anticapitalista. E, para isso, é necessário uma boa dose de empatia entre todxs e sororidade entre as mulheres.

Durante os mais de dois séculos desde que as primeiras ideias feministas surgiram, o movimento que vem se construindo através de ondas - compreendidas aqui como determinados momentos históricos, em que movimentos organizados reivindicatórios ocorreram e culminaram em avanços sociais, econômicos e políticos para as mulheres (BIROLI, 2014) - passou por muitos reveses.

Algumas autoras divergem quanto aos nomes dados às diferentes ondas feministas e sua periodicidade. Contudo, a compreensão da maioria é que tivemos, desde o século XIX, três ondas feministas que se diferenciaram principalmente em termos de demandas e reivindicações dos grupos que lideraram esses movimentos. Exemplo disso, apresentado nas obras de feministas negras como bell hooks ${ }^{4}$ (2013) e Djamila Ribeiro (2018), é a segregação dos

\footnotetext{
${ }^{4}$ bell hooks é o pseudônimo de Gloria Jean Watkins, escritora norte-americana, cujo nome (bell hooks) foi escolhido em homenagem aos sobrenomes da mãe e da avó. O nome, entretanto, grafado em letras minúsculas marcam, para a pensadora, uma forma de defender que o que importa em seus textos e reflexões são suas ideias, ou seja, sua substância. Neste texto, reconhecendo nesta posição a importância estilística, linguística e
} 


\section{$=$ TRAMA $=$}

movimentos de feministas brancas e negras nos Estados Unidos, que ocorreu durante todas as ondas e ainda hoje é forte em meio a esses movimentos sociais, em todas as partes do mundo.

Existe ainda, por parte de muitas feministas brancas, uma resistência muito grande em perceber que, apesar do gênero nos unir, há outras especificidades que nos separam e afastam. Enquanto feministas brancas tratarem a questão racial como birra e disputa, em vez de reconhecer seus privilégios, o movimento não vai avançar, só reproduzir as velhas e conhecidas lógicas de opressão (RIBEIRO, 2018, p. 53).

hooks (2013) nos conta como foi difícil, no início de sua carreira, ser aceita como escritora negra e feminista por ser considerada uma ameaça às feministas brancas, que não aceitavam discutir sobre raça e classe. Além disso, a autora também não era bem vista por negras que entendiam que as discussões feministas tratavam apenas das questões das brancas (o que foi uma realidade por algumas décadas).

Muitas negras ativamente engajadas no movimento feminista falavam sobre o racismo na tentativa sincera de criar um movimento inclusivo que justasse as mulheres brancas e as negras. Acreditávamos que a verdadeira irmandade feminina não surgiria sem a confrontação radical, sem que as feministas investigassem e discutissem o racismo das mulheres brancas e a reação das mulheres negras. [...] A maioria das brancas desconsiderava nossa atitude, julgando-a 'muito raivosa ', e se recusava a refletir criticamente sobre as questões levantadas. Quando as brancas ativas no movimento feminista por fim se dispuseram a reconhecer o racismo, a responsabilidade pelos atos do passado e seu impacto sobre as relações entre mulheres brancas e mulheres de cor, muitas negras estavam arrasadas e esgotadas. Sentimo-nos traídas; as brancas não haviam cumprido a promessa da irmandade (HOOKS, 2013, p. 139).

As percepções de Djamila Ribeiro e bell hooks expõem a falta de empatia e de sororidade que implacavelmente fizeram parte das vivências narradas por Carolina Maria de Jesus e Manuela D'Ávila. Ambas compartilham conosco vivências violentas, cujos algozes eram mulheres como elas:

Hoje uma mulher me agrediu - verbalmente e com muita violência (...) - quando estava com Laura tomando café da manhã no hotel, antes de trabalhar. (...) Eu não entendo nunca agressão. Mas menos ainda quando uma criança está junto com sua mãe. E era uma mulher, era mulher. Uma mulher. Que não conseguiu calar seu ódio diante de uma mãe que abria o braço para proteger a filha (D’ÁVILA, 2019, p. 160).

Trabalhei apreensiva e agitada. A minha cabeça começou doer. Elas costuma esperar eu sair para vir no meu barracão e expancar os meus filhos. (...) O dia de hoje foi benefico. As rascoas da favela estão vendo eu escrever e sabe que é contra elas. Resolveram me deixar em paz. Nas favelas, os homens são mais tolerantes, mais delicados. As bagunceiras são as mulheres. As intrigas delas é igual a de Carlos Lacerda que irrita os nervos. E não há nervos que suporta. Mas eu sou forte! (...) Não me abato (JESUS, 2014 [1960], p. 19; 21).

Para falar sobre a falta de sororidade entre mulheres, Manuela comenta, numa passagem onde explica que sua filha, então com dois anos e meio, considerava normal que sua mãe e a ex-mulher do seu pai tivessem uma relação amistosa. "Ela ainda não sabe que são duas mulheres que como muitas outras foram construídas socialmente para serem inimigas: a

epistemológica para o pensamento desenvolvido pela autora, utilizaremos o nome de bell hooks em letras minúsculas. 


\section{$=$ TRAMA $=$}

atual e a ex, a mãe e a madrasta” (D’ÁVILA, 2019, p. 175). E completa: “(...) o ódio entre mulheres é ensinado. É cultivado fortemente nos contos de fada e reproduzido em nossa cultura todos os dias" (D’ÁVILA, 2019, p. 176).

Diferentemente do feminismo, que vem sendo construído através de ondas, o machismo não é uma onda. Ele é, na verdade, estruturante e extremamente arraigado aos valores morais valorizados por nossa sociedade capitalista e conservadora. Para desnaturalizá-lo, é relevante que se promovam a escuta e a criação de redes de solidariedade entre as mulheres, onde a empatia seja o fundamento máximo, a fim de que nos reconheçamos enquanto minoria que, mesmo tendo agendas próprias (distintos coletivos, como o de mulheres negras, de lésbicas, de prostitutas, de mães pelo parto humanizado, etc), temos em comum a luta para enfraquecer a onda conservadora que nos oprime, nos limita, nos deslegitima, nos violenta e nos mata.

A partir das reflexões que brotam das contundentes narrativas de Manuela e Carolina, também trazemos uma discussão que elucida o motivo de mulheres estarem tão pouco representadas na política e ocuparem um percentual tão baixo de cargos de liderança/ chefia/ poder. Segundo algumas teóricas feministas, a desigualdade de gênero reside na desigual ocupação dos espaços públicos e privados.

No livro de Manuela, por exemplo, percebemos seu incômodo com o fato da presença da sua filha no espaço público chamar mais atenção do que a ausência dos filhos dos políticos do sexo masculino. Em diversas passagens, Manuela problematiza essa questão:

É preciso um mundo em que mulheres ocupem espaços públicos e onde a ausência das crianças seja tão marcante quanto sua presença. Porque pra cada homem poderoso com filhos ausentes existe uma mulher trancada em casa depois do expediente (D'ÁVILA, 2019, p.115).

(...) enquanto um homem brilha construindo a sua carreira, tem uma mãe abrindo mão da sua dentro de casa. (...) Quando a gente mudar a nossa cultura, vai achar estranho o pai que nunca está com seus filhos. Alguém está. Esse alguém é a mãe. Isso tem relação com mulheres não ocuparem espaço público. É fácil, fácil para um homem. Quando desfila com o filho, vira mito (D’ÁVILA, 2019, p.168).

Carolina, por sua vez, narra as desventuras de criar três filhos sem marido e sem ajuda de ninguém. Ela saía para catar papel e deixava os filhos em casa, trancados e com medo das vizinhas, que vinham espancá-los. Muitas vezes, a Carolina teve a sua já exaustiva rotina acentuada por ter que carregar a filha caçula enquanto andava pela cidade, catando papel. Por outro lado, a escritora preferia ser mãe solo a ter que aceitar as condições - muitas vezes violentas - de viver com um homem.

A minha porta atualmente é theatro. Todas as crianças jogam pedras, mas os meus filhos são os bodes expiatorios. Elas alude que eu não sou casada. Mas eu sou mais feliz do que elas. Elas tem marido. Mas, são obrigadas a pedir esmolas (JESUS, 2014 [1960], p.17).

Os meus filhos não são sustentados com pão de igreja. Eu enfrento qualquer especie de trabalho para mantê-los. E elas [as vizinhas], tem que mendigar e ainda apanhar. (...) Não invejo mulheres casadas da favela que levam vida de escravas indianas. Não casei e não estou descontente. Os que preferiu me eram soezes e as condições que eles me impunham eram horriveis" (JESUS, 2014, p.17).

Segundo Engels (apud D 'ALTRI, 2011), a primeira opressão de classe do mundo se deu com a divisão do trabalho entre homem e mulher na monogamia. Essa divisão sexual do trabalho é o principal responsável pela desigualdade de gênero a qual somos submetidas. As 


\section{$=$ TRAMA $=$}

obrigações no âmbito doméstico, vistas pela sociedade como majoritariamente de responsabilidade das mulheres, impõem renúncias às outras esferas da vida. O trabalho não remunerado realizado no lar além de ser desvalorizado ou subvalorizado, limita ou impossibilita a mulher de se dedicar a um trabalho bem remunerado e amplia a possibilidade de o marido dedicar mais tempo ao trabalho e/ou ao lazer.

Além disso, a distribuição de papéis distintos está na base da ideia de que existiriam talentos e tendências naturalmente diferenciados entre os sexos. Expectativas convencionais sobre o papel da mulher, especialmente aquelas que definem seu valor a partir da capacidade de cuidar dos outros e de renunciar a seus interesses, podem permanecer mesmo em meio às transformações na atuação e na autopercepção das mulheres, assim como na multiplicação dos tipos de arranjo nos casamentos (BIROLI, 2014, p. 50).

Recorrendo a Foucault (2010), entendemos que muitos mecanismos e instituições foram criados e/ou colocados a serviço do controle dos corpos femininos, tão fundamentais na reprodução da força de trabalho e do enorme contingente de exército de reserva necessário à manutenção da relação opressão-dominação do capitalismo. A mesma tecnologia a serviço da biopolítica do Estado, que manteve mulheres encarceradas no desvalorizado espaço privado/ doméstico da reprodução e do cuidado, também é utilizada para criar laços entre maternagem e benemerência, conforme nos apresenta Mott (2001):

Na virada do século XX, o reconhecimento da importância das mulheres devido à maternidade já estava solidificado na sociedade brasileira e era aceito por homens e por mulheres. O discurso das esferas separadas tinha cumprido seu papel. Se essa qualidade - a "natureza feminina" - foi usada em muitos casos para segregar as mulheres ao lar e como argumento para impedir a obtenção de direitos civis, políticos, econômicos, intelectuais e sociais, começou também a ser usada num sentido inverso: para lhes abrir as portas e levar as aptidões maternas para fora de casa, para o exercício de determinadas profissões consideradas próprias às mulheres, como a assistência social compatível com a "missão altruística" das mães e, até mesmo, para o exercício dos direitos políticos devido a uma "moralidade" específica ao sexo feminino (MOTT, 2001, p. 211).

Assim, relegar às mulheres uma missão altruística de caridade (a assistência social era vista assim até poucas décadas atrás) era uma maneira conveniente de calar as reivindicações por direitos civis e políticos, sem, na verdade, dar às mulheres o espaço na esfera pública requerido, silenciando assim lugares de fala.

Ainda que brevemente, consideramos necessário discorrer sobre o que entendemos por "lugar de fala". Para isso, damos as mãos, novamente, a Djamila Ribeiro (2017, p. 58), que diz: "acreditamos que este [termo "lugar de fala"] surge a partir da tradição da discussão sobre feminist standpoint - ponto de vista feminista, em uma tradução literal - diversidade, teoria radical crítica e pensamento decolonial". Apesar de não haver uma epistemologia determinada sobre o conceito, conforme afirma Djamila, a autora entende que esse ponto de vista não é individual e sim um lócus social, ou seja, exprime a visão de determinados grupos sociais que buscam dar voz e visibilidade a suas (dificuldades de) existências. "Não estamos falando de indivíduos necessariamente, mas das condições sociais que permitem ou não que esses grupos acessem lugares de cidadania" (RIBEIRO, 2017, p. 61). Assim, Djamila explica que essa definição não tem relação "com uma visão essencialista de que somente o negro pode falar sobre racismo, por exemplo" (Ibid, p. 64).

Para ela, lugar de fala é diferente de representatividade, por falar a partir de lugares/ posições sociais. É também "romper com a lógica de que somente subalternos falem de suas 


\section{$=$ TRAMA $=$}

localizações, fazendo com que aqueles inseridos na norma hegemônica sequer se pensem" (Ibid, p. 84). Assim, entendemos que todos possuem lugares de fala, visto que consideramos muito importante fortalecer a ideia de que "indivíduos pertencentes ao grupo social privilegiado em termos de lócus social consigam enxergar as hierarquias produzidas a partir desse lugar e como esse lugar impacta diretamente na constituição dos lugares dos grupos subalternizados" (Ibid, p. 86). Pensar em lugar de fala é ter uma postura ética.

Por essa razão, enfatizamos o quanto Carolina era consciente do seu lugar de fala/ pertencimento e de todas as opressões e discriminações que sofria por fazer parte do grupo social das mulheres negras/ pobres/ faveladas/ sem emprego/ mães solo. Manuela, do mesmo modo, tem noção dos privilégios que acumula por ser branca/ classe média/ política/ escolarizada/ mãe com parceiro. Contextos, tempos e espaços muito distantes separam ambas, porém os sofrimentos e violências experimentados e narrados precisam ser valorizados e legitimados.

\section{POTÊNCIA GERA POTÊNCIA}

Embora haja aqueles que sobre as duas autoras por nós destacadas ainda não se inteiraram, há outros tantos que não somente com elas se identificam, como passam, a partir delas, a assumir os seus próprios lugares de fala. Este é o caso de Marielle, pseudônimo dado a uma adolescente e estudante do Ensino Médio de uma escola pública do interior do Rio de Janeiro, em homenagem à Marielle Franco, vereadora vítima de feminicídio político, em março de 2018, que teve a vida e luta reconhecidas em sua morte.

Marielle é aluna, negra, pobre e, apesar dos seus recém-completos dezesseis anos, já luta. Vítima de situações discriminatórias, Marielle aceitou o convite para conhecer Carolina Maria de Jesus. "Quarto de Despejo: Diário de uma Favelada" entrou no quarto de Marielle e proporcionou uma identificação entre a mulher de cinquenta e nove anos atrás e a garota de hoje. Marielle foi ao passado e Carolina manifestou-se no presente.

Ao invés de parafrasearmos suas palavras, escolhemos nos retirar a fim de que Marielle ocupe seu justo espaço. A aluna empoderou-se ao se reconhecer em Carolina e ao reconhecer que, embora a autora também fosse vítima de violências, o silêncio não foi sua escolha. Pode parecer a boa e velha brincadeira do telefone sem fio, mas Carolina falou com Marielle. Marielle já escuta Manuela D’Ávila. Marielle a nós mostra presença e potência nas linhas que seguem.

Eu sinceramente esperava que o livro de Carolina me fizesse refletir sobre a minha vida, mas não esperava que, depois daquela leitura, eu mudaria. Foi surpreendente saber que há 59 anos atrás já havia uma mulher que buscava por sua independência, ter suas próprias conquistas, que já tomava suas próprias decisões em relação à política, ao corpo, ao cabelo, ao casamento.

Ler Carolina foi pura descoberta, foi me conectar com a história a ponto de reconhecer em Carol (eu a chamo assim) a minha própria mãe. Foi incrivel descobrir que eu não estava sozinha e que, assim como eu, Carolina também havia passado por situações de preconceito e buscava superar todas as suas dificuldades. Carolina me motivou.

Quando Carol fala que adora sua pele negra e o seu cabelo, que acha o cabelo de preto mais educado, eu iniciei um processo de aceitação em mim. Junto com outros acontecimentos, tive coragem de cortar meu cabelo bem curtinho e me livrar da ideia de cabelos lisos serem melhores e mais bonitos. Essa foi a melhor coisa que eu poderia fazer por mim.

Quando ela imagina a possibilidade de reencarnar negra, eu fiquei arrepiada. Mais ainda quando ela também fala de quando era criança e sonhava em ser homem para defender o Brasil, pois quando leu um livro de história, só encontrou assinaturas de homens. Essas coisas me fizeram refletir. 


\section{$=\mathrm{T} R A M A=$}

Se alguém me perguntasse se eu voltaria negra e mulher, minha resposta seria mil vezes SIM, mesmo sabendo de tudo que uma mulher ainda sofre durante a sua trajetória. Depois de voltar o meu olhar pra mim mesma e para as mulheres em minha volta, sempre estufarei o peito e responderei que sim.

\section{CONSIDERAÇÕES FINAIS}

Escrever sobre Manuela D’Ávila e Carolina Maria de Jesus foi pura responsabilidade deleitosa. Falar sobre essas duas autoras foi assumir o compromisso de manter a ressonância de suas vozes, ainda que soubéssemos que nossas páginas apenas chegariam perto do que consideramos apreciável diante de obras tão fortes. Entretanto, o esforço das palavras aqui gravadas é fazer com que nossxs leitorxs fitem/ se emocionem/ se sintam representadxs e, especialmente, empatizem com as vivências por elas narradas.

Essas duas mulheres possuem bastante consciência de seus lugares de fala. A leitura empática de suas obras bem como a escuta empática de suas vozes nos fazem (re)visitar conceitos, desconstruir estereótipos, refletir acerca de questões inadiáveis e nos posicionar diante de temáticas inquietantes.

Não temos por ambição outra coisa senão provocar uma espécie de ruminação. As mulheres que aqui nos acompanham parecem acertar sentidos. Ouvimos rugidos. Olhamos empaticamente. Cremos, agora, ser interessante degustar as palavras aqui servidas. As mesmas que alimentaram Carolina, encheram Manuela e saciaram Marielle. As mesmas que sustentam e fortalecem as muitas outras que ainda estão por vir.

\section{REFERÊNCIAS BIBLIOGRÁFICAS}

ARRUZZA, C., BHATTACHARYA, T., FRASER, N. Feminismo para os 99\% - um manifesto. 1a ed. São Paulo: Boitempo, 2019.

BIROLI, F. Justiça e família. In: MIGUEL, L.F. e BIROLI, F. Feminismo e política. 1a ed. São Paulo: Boitempo, 2014.

CRENSHAW, K. Documento para o encontro de especialistas em aspectos da discriminação racial relativos ao gênero. In: Estudos Feministas. Ano 10, p.171-188, 2002.

D’ALTRI, A. Feminismo e marxismo: 40 anos de controvérsias. In: Lutas sociais. n.27. São Paulo, 2o sem 2011.

D’ÁVILA, Manuela. Revolução Laura: reflexões sobre maternidade e resistência. Caxias do Sul: Rio Grande do Sul, Belas Letras, 2019.

FOUCAULT, M. Em defesa da sociedade. 2a ed. São Paulo: Martins Fontes, 2010.

FREIRE, Paulo Freire. Pedagogia da indignação: cartas pedagógicas e outros escritos. São Paulo: Editora UNESP, 2000.

HOOKS, B. Ensinando a transgredir: a educação como prática de liberdade. São Paulo: Editora WMF Martins Fontes, 2013.

JESUS, Carolina Maria de. Quarto de despejo: diário de uma favelada. 10a. ed. São Paulo: Ática, 2014. LAJOLO, Marisa. A Leitora no Quarto dos Fundos. In: Leitura: Teoria \& Prática. Ano 14, nº. 25, p.10, jun./1995.

MEIHY, José Carlos Sebe Bom. Carolina Maria de Jesus: emblema do silêncio. In: Revista USP. São Paulo (37): 82 - 91, março/maio, 1998.

MOTT, M.L. Maternalismo, políticas públicas e benemerência no Brasil (1930-1945). In: Cad. Pagu,

Campinas, n.16, pp.199-234, 2001.

RIBEIRO, D. O que é lugar de fala? Belo Horizonte (MG): Letramento. 2017

. Quem tem medo do feminismo negro? 1a ed. São Paulo: Companhia das Letras, 2018. 